\title{
Predation by the mysid shrimps Mysis mixta and M. relicta on benthic eggs of Bosmina longispina maritima (Cladocera) in the northern Baltic Sea
}

\author{
Satu Viitasalo ${ }^{1,2, *}$, Markku Viitasalo $^{3}$ \\ ${ }^{1}$ Department of Biological and Environmental Sciences, University of Helsinki, PO Box 65, 00014 Helsinki, Finland \\ ${ }^{2}$ Tvärminne Zoological Station, 10900 Hanko, Finland \\ ${ }^{3}$ Finnish Institute of Marine Research, PO Box 33, 00931 Helsinki, Finland
}

\begin{abstract}
The abundance of Bosmina longispina maritima (Cladocera), the most common water flea in the Baltic Sea, shows considerable interannual fluctuations. The number of Bosmina resting eggs (ephippia) in the sediment also fluctuates from year to year. Biotic as well as abiotic factors have been suggested to contribute to these fluctuations, but the impact of benthic predation by pelagic mysids has not yet been considered. The objective of this study was to investigate the effect of benthic predation and bioturbation by Mysis mixta and M. relicta on the ephippia of $B$. longispina maritima on the SW coast of Finland. The results show that mysids can significantly affect the number of Bosmina eggs in the sediment. All size groups of both mysid species preyed upon ephippia of $B$. longispina maritima both in the water column and directly from the top layer of sediment, whereas they rejected the eggs of another cladoceran species, Pleopsis polyphemoides. The predation rate on $B$. longispina maritima ephippia was significantly lower when the eggs were buried under a sediment layer of ca. $1 \mathrm{~cm}$. This suggests that factors affecting the vertical distribution of ephippia in the sediment determine the magnitude of the impact that mysids have on B. longispina maritima benthic eggs.
\end{abstract}

KEY WORDS: Bosmina longispina maritima $\cdot$ Resting eggs $\cdot$ Mysis mixta $\cdot$ M. relicta $\cdot$ Benthic predation $\cdot$ Baltic Sea

\section{INTRODUCTION}

Bosmina longispina maritima (P. E. Müller), an endemic brackish water cladoceran of the Baltic Sea, belongs to the 5 most abundant mesozooplankton species in the northern Baltic (Viitasalo 1992). The abundance of B. longispina maritima (hereafter termed Bosmina) shows considerable interannual fluctuations, the summertime biomass maximum ranging from virtually zero to ca. 50 ind. $\mathrm{l}^{-1}$ (e.g. Purasjoki 1958, Viitasalo et al. 1995). While various abiotic and biotic conditions regulate zooplankton abundance and production in the northern Baltic (Viitasalo et al. 1995, Uitto et al. 1997), the proximate causes for the fluctuations observed in Bosmina populations still remain unclear. In addition to temperature, salinity and stratification, biotic factors such as predation and benthic processes have been suggested to contribute to zooplankton dynamics in the Baltic (Albertsson \& Leonardsson 2000, 2001).

Under favourable food and weather conditions in summer, intensive parthenogenetic reproduction enables Bosmina populations to increase rapidly (Purasjoki 1958). Later in the season, when environmental conditions start to deteriorate, Bosmina produces overwintering diapause eggs before disappearing from the plankton (Purasjoki 1958, Kankaala 1983). These sexually produced 'ephippia' sink onto the bottom and can survive within the sediment for at least a decade (Viitasalo \& Katajisto 1994). Just as the size of the pelagic population varies between years, so does the 
number of ephippia in the bottom (Kankaala 1983). The average density of Bosmina ephippia in the study area may be as high as 20000 ind. $\mathrm{m}^{-2}$ (Viitasalo \& Katajisto 1994). According to Kankaala (1983), abrupt population increases of Bosmina in the pelagic zone are largely caused by hatching of benthic eggs. Therefore factors affecting the abundance and hatching of ephippia in the sediment probably play an important role in the annual recruitment of Bosmina.

Two species of pelagic mysid shrimps, Mysis mixta and $M$. relicta, are abundant and important invertebrate zooplanktivores in the northern Baltic (Salemaa et al. 1986, Rudstam et al. 1992). They feed on both phyto- and zooplankton in the pelagial, as well as detritus and other benthic material on the bottom (Viherluoto et al. 2000). Mysids are capable of both filter- and raptorial feeding, and their prey size ranges from detrital matter and microplankton to mesozooplankton such as adult copepods and cladocerans (Mauchline 1980, Grossnickle 1982, Rudstam et al. 1989). Together with the other major planktivore group in the Baltic Sea, the clupeids (herring and sprat), mysids significantly contribute to the seasonal decline of zooplankton in the autumn (Hansson et al. 1990, Rudstam et al. 1992). Both Mysis species perform diurnal vertical migrations, spending the daylight hours near the bottom and ascending towards surface waters at night (Salemaa et al. 1986, Rudstam et al. 1989). Due to their omnivorous feeding habits combined with the vertical migration, mysids potentially have an important impact on both the pelagic and benthic food webs in the northern Baltic.

Benthic processes affect the recruitment of zooplankton resting stages into plankton (e.g. Marcus 1984, Marcus \& Schmidt-Gengenbach 1986, Kearns et al. 1996, Albertsson \& Leonardsson 2001). Animals feeding and burying in the sediment thus affect the survival and hatching probability of zooplankton resting eggs directly, by predation, and indirectly, by modifying sediment structure and oxygen levels in the sediment. However, few studies have investigated the effects of benthic processes on brackish water cladocerans, and to our knowledge none have considered the impact of mysids on zooplankton resting eggs in the marine environment.

Our objective was to reveal whether the dominant open sea mysids of the Baltic Sea, Mysis mixta and $M$. relicta, have the potential to influence Bosmina abundance through predation on their resting eggs. We conducted a series of laboratory experiments to determine whether pelagic mysids feed on Bosmina resting eggs, either directly from the water column or from the surface sediments. Eggs of another common cladoceran, Pleopsis polyphemoides, were included in the first experiment (Expt 1A), to compare the predation of the mysids on the 2 cladoceran species. Another experiment was made to elucidate whether there is a size limit for mysids feeding on Bosmina eggs (Expt 1B). Furthermore, we compared the feeding rate of mysids on Bosmina eggs to those on live and dead (adult) Bosmina (Expt 2), and determined whether the predation of mysids on Bosmina eggs is affected by the availability of alternative food, i.e. phytoplankton (Expts 1A and 1B) or zooplankton (Expt 3). Finally, we investigated whether mysids feed on ephippia buried in the sediment (Expt 4).

\section{MATERIALS AND METHODS}

Collection of material. The material for the experiments was collected on the coast of the Hanko Peninsula, SW Finland, during June to September 2001 (Expts 1 to 3, see below) and September 2002 (Expt 4). Mysids were collected in the daytime at 'Längden' $\left(59^{\circ} 45.58^{\prime} \mathrm{N}, 23^{\circ} 15.23^{\prime} \mathrm{E}\right)$, a 50 to $80 \mathrm{~m}$ deep open sea area, by an epibenthic sledge (mouth opening $41 \times$ $23 \mathrm{~cm}$, net length $115 \mathrm{~cm}, 1 \mathrm{l}$ cod end). The sledge was lowered down to 1 to $2 \mathrm{~m}$ above the bottom and dragged at ca. 0.9 knots for ca. $500 \mathrm{~m}$. The mysids were immediately transferred into a $30 \mathrm{l} \mathrm{cool} \mathrm{box} \mathrm{filled} \mathrm{with}$ natural seawater collected from below the thermocline and were transported into a temperature regulated room $\left(13\right.$ to $\left.15^{\circ} \mathrm{C}\right)$. Mysid species were identified under a binocular microscope and individuals were classified into 4 groups on the basis of their body size and sexual maturity. Pelagic mysids shift gradually from a more benthic and herbivorous diet to a more carnivorous one as individuals reach a size of 8 to $11 \mathrm{~mm}$ (Viherluoto et al. 2000). To investigate whether this ontogenetic shift affects mysid predation on ephippia, we chose 3 mysid length groups for our experiments: $<7 \mathrm{~mm}$ ('small'), 7-12 $\mathrm{mm}$ ('medium') and >12 mm ('large'). In addition, post-spawned females were separately grouped on the basis of sexual characters (marsupium). The mysids were acclimatised to prevailing temperature and light cycle conditions (light:dark 16:8 h) for at least $24 \mathrm{~h}$ in gently aerated containers with natural plankton (mainly consisting of calanoid copepods). Before the experiments, the mysids were transferred into $0.2 \mu \mathrm{m}$ filtered seawater (FSW) and starved for $12 \mathrm{~h}$.

Muddy surface sediment (light brown in color) (Expt 4) as well as cladoceran eggs were collected at Storfjärden $\left(59^{\circ} 51.31^{\prime} \mathrm{N}, 23^{\circ} 15.98^{\prime} \mathrm{E}\right)$, a nearby archipelago area $35 \mathrm{~m}$ deep, by an Ockelmann detritus sledge (mouth opening $12 \times 30 \mathrm{~cm}$, net length $52 \mathrm{~cm}$, mesh size $100 \mu \mathrm{m})$. To separate eggs from sediment, we used the sugar flotation method developed by Onbé (1978). The sediment was sieved through a 
$100 \mu \mathrm{m}$ mesh and the material remaining on the sieve was washed into $50 \mathrm{ml}$ centrifugation tubes with sugar solution (500 $\mathrm{g}$ of sugar in $500 \mathrm{ml}$ of water). The mixture was then centrifuged at $3000 \mathrm{rpm}$ for $3 \mathrm{~min}$ to separate cladoceran eggs, which remained floating in the supernatant, from heavier particles that sank onto the bottom of the centrifuge tube. In addition, live Bosmina were collected at Storfjärden with vertical hauls from $25 \mathrm{~m}$ to the surface using a $150 \mu \mathrm{m}$ mesh plankton net (opening diameter ca. $40 \mathrm{~cm}$ ).

Experiments on pelagic predation. This study consisted of 4 experiments (see Table 1 for duration, mysid species and size groups, types of prey, predator and prey densities, and number of replicates). Expts 1 to 3 simulated the predation of Mysis spp. on Bosmina ephippia suspended in the water column. These experiments were performed in $1.18 \mathrm{l}$ glass bottles filled with $0.2 \mu \mathrm{m}$ FSW. We used prey densities of 4, 17 and 42 prey $\mathrm{l}^{-1}$, ranging around the average maximum densities of Bosmina in the field ( 20 ind. $\mathrm{l}^{-1}$; Kankaala 1983, Viitasalo et al. 1995), except in Expt 3, in which the density was considerably higher (85 prey $\mathrm{l}^{-1}$ ). Mysids were added into bottles ( 3 ind. bottle ${ }^{-1}$ in Expt 1 and 1 ind. bottle ${ }^{-1}$ in Expts 2 \& 3), the bottles were sealed with a plastic film (preventing disturbance by air bubbles in the bottles) and attached onto a plankton wheel rotating at low speed $(0.25 \mathrm{rpm})$ to keep the particles suspended. Because predation rates of pelagic mysids are higher in darkness (Viherluoto \& Viitasalo 2001a), we conducted all experiments in darkness except the $12 \mathrm{~h}$ long experiments (Expt 1A,B \& 4), in which the mysids were $8 \mathrm{~h}$ in darkness and $4 \mathrm{~h}$ in light. Due to the $4 \mathrm{~h}$ light period, feeding rates may have been underestimated in these longer experiments. To check the predator-independent loss of prey during the experiments, control bottles without mysids, treated in the same manner as treatment bottles, were included in all experiments. At the end of the incubations, the bottles were emptied onto a sieve, and the prey and the mysids were preserved with Lugol's solution. The remaining prey were counted under a binocular microscope and the predation rate (prey mysid ${ }^{-1} \mathrm{~h}^{-1}$ ) was determined as the difference of the number of prey remaining in the treatment and control bottles. Recovery of prey in control bottles was $73 \%$ in Expt $1 \mathrm{~A}$, $85 \%$ in Expt 1B, $100 \%$ in Expt 2 and $100 \%$ in Expt 3.

In Expt $1 \mathrm{~A}$ ( $\mathrm{n}=3$ to 4 experimental and 3 to 4 control incubations), juvenile Mysis mixta (5.4 to $10.0 \mathrm{~mm}$ from

Table 1. Overview of experiments on predation by Mysis spp. on Bosmina longispina maritima. Mysid size groups: S: <7 mm, M: 7-12 mm, L: 12-18 mm, P (postspawned): >20 mm. Eph: Bosmina ephippia; micropl.: microplankton. Mysid densities of 1 and 3 ind. bottle ${ }^{-1}$ correspond to 0.8 and 2.5 ind. $^{-1}$, respectively. $\mathrm{n}$ : number of replicate incubations

\begin{tabular}{|c|c|c|c|c|c|c|}
\hline $\begin{array}{l}\text { Expt } \\
\text { Duration (h) }\end{array}$ & $\begin{array}{l}\text { Mysis } \\
\text { species }\end{array}$ & $\begin{array}{c}\text { Mysid } \\
\text { size group }\end{array}$ & $\begin{array}{l}\text { Mysid density } \\
\left(\text { bottle }^{-1}\right)\end{array}$ & Prey & $\begin{array}{l}\text { Prey density } \\
\quad\left(\text { prey l }^{-1} \text { ) }\right.\end{array}$ & $\mathrm{n}$ \\
\hline \multicolumn{7}{|c|}{ 1A: Predation on cladoceran eggs } \\
\hline \multirow[t]{3}{*}{12} & M. mixta & $\mathrm{S}$ to $\mathrm{M}^{\mathrm{a}}$ & 3 & eph & 25 & 4 \\
\hline & & & & eph + micropl. $(<40 \mu \mathrm{m})$ & 25 & 4 \\
\hline & & & & Pleopsis eggs & 8 & 3 \\
\hline \multicolumn{7}{|c|}{ 1B: Size-class experiment } \\
\hline \multirow[t]{5}{*}{12} & M. mixta & $\mathrm{S}^{\mathrm{b}}$ & 3 & eph & 21 & 3 \\
\hline & & & & eph + micropl. $(<100 \mu \mathrm{m})$ & 21 & 3 \\
\hline & & $\mathrm{M}^{\mathrm{c}}$ & 3 & eph & 21 & 3 \\
\hline & & & & eph + micropl. $(<100 \mu \mathrm{m})$ & 21 & 3 \\
\hline & & $L^{d}$ & 3 & eph & 21 & 3 \\
\hline \multicolumn{7}{|c|}{ 2: Functional response } \\
\hline \multirow[t]{3}{*}{2} & M. mixta & $\mathrm{L}^{\mathrm{e}}$ & 1 & eph & $4,17,42$ & 6 \\
\hline & & & & live Bosmina & $4,17,42$ & 4 \\
\hline & & & & dead Bosmina & $4,17,42$ & 4 \\
\hline \multicolumn{7}{|c|}{ 3: Prey selection } \\
\hline 4 & M. mixta & $\mathrm{M}^{\mathrm{f}}$ & 1 & eph + live Bosmina & $25+85$ & 4 \\
\hline \multicolumn{7}{|c|}{ 4: Benthic predation } \\
\hline \multirow[t]{7}{*}{12} & M. mixta & $L^{g}$ & 1 & eph on top of sediment & $8000^{\mathrm{j}}$ & 12 \\
\hline & & & & eph within sediment & $8000^{\mathrm{j}}$ & 12 \\
\hline & & $\mathrm{P}^{\mathrm{h}}$ & 1 & eph within sediment & $8000^{\mathrm{j}}$ & 11 \\
\hline & M. relicta & $M^{\mathrm{i}}$ & 1 & eph on top of sediment & $8000^{\mathrm{j}}$ & 10 \\
\hline & & & & eph within sediment & $8000^{j}$ & 10 \\
\hline & & $L^{g}$ & 1 & eph on top of sediment & $8000^{j}$ & 10 \\
\hline & & & & eph within sediment & $8000^{j}$ & 10 \\
\hline
\end{tabular}


the tip of the rostrum to the end of the telson) were offered benthic eggs of 2 cladoceran species, Bosmina ephippia (size ca. $460 \mu \mathrm{m}$ ) and spherical resting eggs of Pleopsis polyphemoides (size ca. $200 \mu \mathrm{m}$; see Viitasalo \& Katajisto 1994). Prior to adding the eggs, the bottles were filled with either $0.2 \mu \mathrm{m}$ or $40 \mu \mathrm{m}$ FSW (from above the thermocline), to check whether addition of natural microplankton $<40 \mu \mathrm{m}$ affects the willingness of mysids to feed on Bosmina ephippia (microplankton was not offered with $P$. polyphemoides eggs).

In Expt 1B ( $\mathrm{n}=3$; controls $\mathrm{n}=3$ ) ephippia were offered, either alone or together with microplankton $<100 \mu \mathrm{m}$, to 3 size classes of Mysis mixta: small, medium and large (see Table 1). A larger size fraction $(<100 \mu \mathrm{m})$ was chosen in Expt $1 \mathrm{~B}$ since $<40 \mu \mathrm{m}$ microplankton appeared to have no effect on predation in Expt 1A. Microplankton was not offered to large mysids.

Expt 2 was designed to determine the functional response of Mysis mixta (large) on ephippia ( $\mathrm{n}=6$; controls $\mathrm{n}=3$ ) and 2 other prey types (live and heat-killed Bosmina) ( $\mathrm{n}=4$; controls $\mathrm{n}=3$ ) in single-prey experiments. All prey were carefully pipetted into bottles filled with $0.2 \mu \mathrm{m}$ FSW at 3 densities: 5, 20 and 50 ind. bottle $\mathrm{e}^{-1}\left(4,17\right.$ and 42 ind. $\mathrm{l}^{-1}$, respectively), and the predation rate was determined as above.

A 2-prey experiment (Expt 3) was conducted to determine whether Mysis mixta (medium) prefer live Bosmina (100 prey bottle ${ }^{-1}$ ) over ephippia (30 prey bottle $^{-1}$ ) when the latter two are provided together. Since a preliminary experiment of $8 \mathrm{~h}$ showed that prey depletion severely affected the results, the experimental period was limited to $4 \mathrm{~h}(\mathrm{n}=4$; controls $\mathrm{n}=4)$.

Experiments on benthic predation. In Expt 4, our objective was to study the impact of both mysid species (Mysis mixta or M. relicta) and 3 size classes (medium, large and postspawned; see Table 1) on Bosmina ephippia in the benthos ( $\mathrm{n}=10$ to 12 replicates). We used muddy surface sediment sieved through a $100 \mu \mathrm{m}$ mesh to remove any ephippia. Then the sediment was added into $1.18 \mathrm{l}$ glass bottles with FSW and allowed to settle. 80 ephippia were pipetted into each bottle, either on top of the sediment (ephippia added after the sediment had settled) or mixed with the sediment (ephippia added to sediment-water mixture and then allowed to settle). The density of 0.4 ephippia $\mathrm{cm}^{-3}$ corresponded to natural densities of ephippia in the top $2 \mathrm{~cm}$ in the study area ( 0 to 3 ind. $\mathrm{cm}^{-3}$; Viitasalo \& Katajisto 1994). After settling, the sediment layer was ca. $2 \mathrm{~cm}$ deep. One mysid was added to each bottle, and the bottles were left uncapped on a table in the temperature controlled room (ca. $15^{\circ} \mathrm{C}$ ).
Twelve h later the experiment was ended in the same manner as the previous experiments. Average recovery rate of prey in the control bottles was $100 \%$ (ephippia mixed within the sediment; $\mathrm{n}=7$ ).

Stomach analysis. In Expt 4, in order to determine whether ephippia can survive in the digestive tract of mysids, the animals were preserved in $4 \%$ buffered formaldehyde solution for stomach content analysis. Mysids were kept in a small amount $(4 \mathrm{ml})$ of seawater $\left(\sim 15^{\circ} \mathrm{C}\right)$ before preservation, within $1.5 \mathrm{~h}$ after ending the experiment; according to Rudstam et al. (1989), several hours or even days are needed for complete gut clearance of $M$. mixta. Mysid stomachs were carefully dissected and the stomach contents were transferred onto a glass slide and studied under an inverted microscope with 100 magnification.

Behavioural analysis. To elucidate the behaviour of mysids on soft sediment bottoms, we videotaped mysids in darkness with an infrared sensitive camera (Mintron MTV-1802CD) with $105 \mathrm{~mm}$ Nikon macro objective, at ca. $15^{\circ} \mathrm{C}$ (for further details see Viitasalo et al. 1998). Large individuals of Mysis mixta were videotaped in a cubic 11 aquarium with sieved sediment on the bottom and ephippia added on top of the sediment. Also, mysids were videotaped in the same 11 aquaria, with ephippia in water, but without sediment. The video was carefully screened and certain sequences were cut as still images using the Adobe Premier program.

Calculations and statistics. Prey selectivity of mysids on the 2 prey types (live Bosmina and ephippia) in Expt 3 was analysed by calculating Ivlev's selectivity index $E_{\mathrm{a}}=\left(\mathrm{a}_{\mathrm{d}} \mathrm{e}-\mathrm{a}_{\mathrm{e}} \mathrm{d}\right) /\left(\mathrm{a}_{\mathrm{d}} \mathrm{e}+\mathrm{a}_{\mathrm{e}} \mathrm{d}\right)$ (Pearre 1982; cf. Table 2). Values of $E_{\mathrm{a}}>0$ indicate positive selection, i.e. preference, and those $<0$ indicate negative selection, i.e. rejection.

The significance of differences in the loss of prey (Expt 1), predation rates (Expts 2 to 4 ) and selectivity indices (Expt 3) between treatments, as well as differences between the control and treatment bottles, were tested with the statistical package SPSS 11.0 for Windows. When data were normally distributed and variances were homogenous, we used a parametric Student's $t$-test or ANOVA, followed by Tukey's post hoc test. When these premises were not fulfilled, we used the non-parametric Mann-Whitney $U$-test or Kruskal-Wallis ANOVA.

Table 2. Parameters for Ivlev's index E (Pearre 1982)

\begin{tabular}{|lccc|}
\hline & Species A & Other species & Total \\
\hline Diet (food items eaten) & $\mathrm{a}_{\mathrm{d}}$ & $\mathrm{b}_{\mathrm{d}}$ & $\mathrm{a}_{\mathrm{d}}+\mathrm{b}_{\mathrm{d}}=\mathrm{d}$ \\
Environment (food items left) & $\mathrm{a}_{\mathrm{e}}$ & $\mathrm{b}_{\mathrm{e}}$ & $\mathrm{a}_{\mathrm{e}}+\mathrm{b}_{\mathrm{e}}=\mathrm{e}$ \\
Total (food items provided) & $\mathrm{a}_{\mathrm{d}}+\mathrm{a}_{\mathrm{e}}=\mathrm{a}$ & $\mathrm{b}_{\mathrm{d}}+\mathrm{b}_{\mathrm{e}}=\mathrm{b}$ & $\mathrm{a}_{\mathrm{d}}+\mathrm{a}_{\mathrm{e}}+\mathrm{b}_{\mathrm{d}}+\mathrm{b}_{\mathrm{e}}=\mathrm{n}$ \\
\hline
\end{tabular}




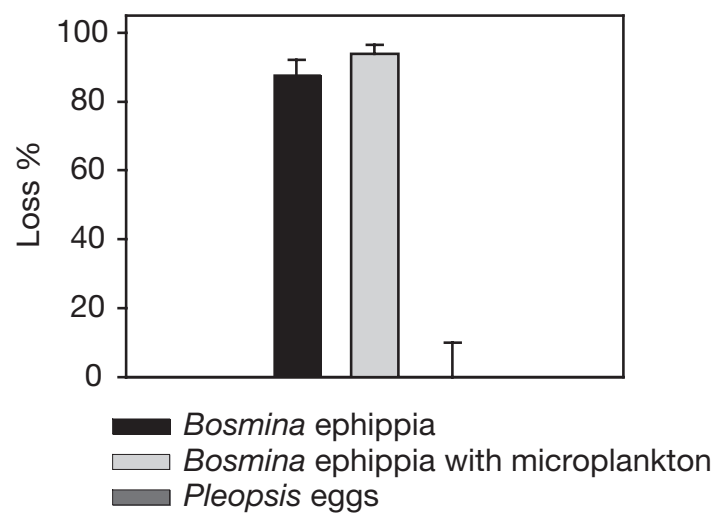

Fig. 1. Mysis mixta. Expt 1A. Percentage of Bosmina longispina maritima ephippia (with and without $<40 \mu \mathrm{m}$ microplankton) and of Pleopsis polyphemoides eggs lost during incubation. Mean $\pm \mathrm{SE}$

\section{RESULTS}

\section{Mysid feeding on cladoceran benthic eggs without sediment}

In Expt 1A Mysis mixta fed actively upon the Bosmina ephippia (76 to $100 \%$ were eaten) whereas the spherical Pleopsis polyphemoides eggs were not attacked (difference in loss \% between the 3 treatments: Kruskal-Wallis $=6.678, \mathrm{df}=2, \mathrm{p}=0.035, \mathrm{n}=4$ ) (Fig. 1). The presence of microplankton $(<40 \mu \mathrm{m})$ did not affect the feeding on ephippia (Tukey's HSD, p = $0.711)$.

In Expt 1B, individuals of all mysid size classes ate ephippia, with losses varying between 86 and 100\%. No significant difference was detected between size classes (Kruskal-Wallis $H=1.508$, df $=2, \mathrm{p}=0.47$, $\mathrm{n}=3)$. Microplankton $(<100 \mu \mathrm{m})$ did not affect predation rates on ephippia: Mann-Whitney $U=3.5$ ( $\mathrm{p}=$ $0.637, \mathrm{n}=3$ ) for small mysids and $U=2.5(\mathrm{p}=0.346$, $\mathrm{n}=3$ ) for medium size mysids.

\section{Functional response}

In Expt 2, 3 alternative models corresponding to Holling response types I, II and III (Holling 1959) were fitted to the data. The linear model $\left(y=y_{0}+a x\right)$, the decreasing rise to maximum model $\left(y=\mathrm{a}\left[1-\mathrm{e}^{-b x}\right]\right)$, and the sigmoidal model $\left(y=\mathrm{a} /\left[1+e^{-\left(x-x_{0} / b\right)}\right]\right)$, explained 41 to 57,42 to 57 and 42 to $57 \%$ of the variation in data, respectively. Since the more complex models did not explain a much larger fraction of the variation, the linear model was chosen to describe the functional response of Mysis mixta with all 3 prey types offered.

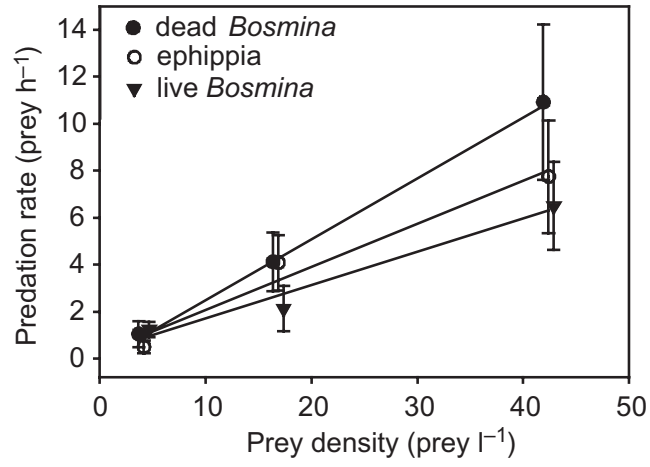

Fig. 2. Mysis mixta. Expt 2. Functional response of M. mixta on ephippia, and on live and dead adults of Bosmina longispina maritima (mean $\pm \mathrm{SE}$ ). Linear regressions for dead Bosmina adults: $y=-0.13+0.26 x\left(\mathrm{r}^{2}=0.57\right)$; ephippia: $y=0.23$ $+0.18 x\left(\mathrm{r}^{2}=0.41\right)$; live Bosmina adults: $y=0.28+0.14 x\left(\mathrm{r}^{2}=\right.$ $0.52)_{i}$ symbols are slightly shifted horizontally for clarity

The slope of the predation rate on dead Bosmina was steeper than those of predation on ephippia or live Bosmina (Fig. 2). However, no statistically significant differences were found (ANOVA $F=0.906$, df $=36$, $\mathrm{p}>0.05, \mathrm{n}=4$ to 6 ; Zar 1984). At the prey densities used ( 4 to 42 prey $\mathrm{l}^{-1}$ ), there was no evidence of saturation of the predation rate.

\section{Prey selection}

In the prey selection experiment (Expt 3), the predation on live Bosmina (21.4 prey $\mathrm{h}^{-1}$ ) was more intense than that on ephippia (5.1 prey $\left.\mathrm{h}^{-1}\right)(t=-20.018, \mathrm{df}=6$, $\mathrm{p}=0.000, \mathrm{n}=4$ ) (Fig. 3A). However, since the initial prey densities were lower for ephippia than for Bosmina (30 ephippia and 100 Bosmina bottle ${ }^{-1}$ ), preference cannot be directly deduced from the predation rates. We therefore calculated Ivlev's selectivity index
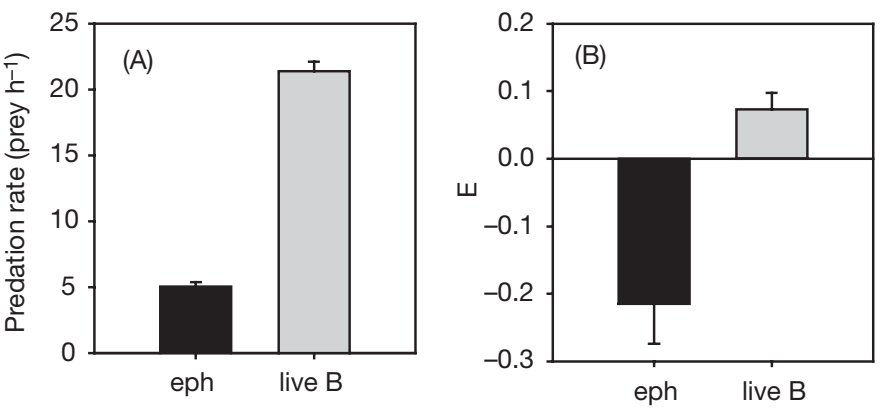

Fig. 3. Mysis mixta. Expt 3. (A) Predation rates on ephippia (eph) and live Bosmina adults (live B) provided together. (B) Ivlev's selectivity index $E$ for predation on ephippia and live Bosmina. Data are mean $\pm \mathrm{SE}$ 

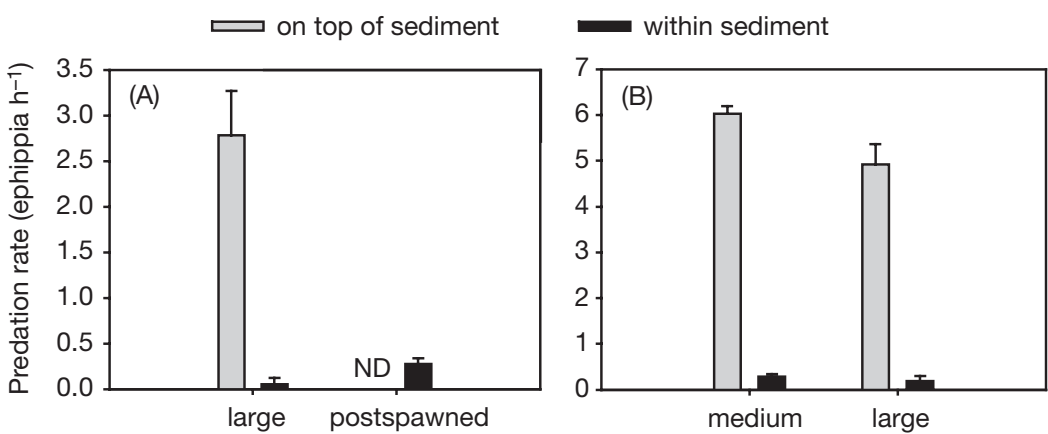

Fig. 4. (A) Mysis mixta and (B) M. relicta. Expt 4. Benthic predation on ephippia of Bosmina longispina maritima on and within sediment. ND = no data. Data are mean $\pm \mathrm{SE}_{\text {; }}$ note the different scales on $y$ axes

$E$, which accounts for relative prey abundances. The average $E$ for ephippia was always negative ( -0.37 to $-0.10)$, while $E$ for adult Bosmina were always positive (0.03 to 0.14) (Fig. 3B). However, the overall indices were low, suggesting low selectivity. When tested with the $\chi^{2}$-test (with Yate's correction for continuity according to Pearre 1982), statistically significant differences were not observed between selection indices for ephippia and Bosmina $\left(\chi^{2}=0.847, \mathrm{df}=1, \mathrm{p}>0.05, \mathrm{n}=4\right)$.

\section{Mysid feeding on cladoceran benthic eggs with sediment}

Both species of pelagic mysid shrimps, Mysis mixta and $M$. relicta, fed actively on ephippia added on top of the sediment (Fig. 4A). Average predation rates ranged from 2.8 ephippia $\mathrm{h}^{-1}$ for large M. mixta to
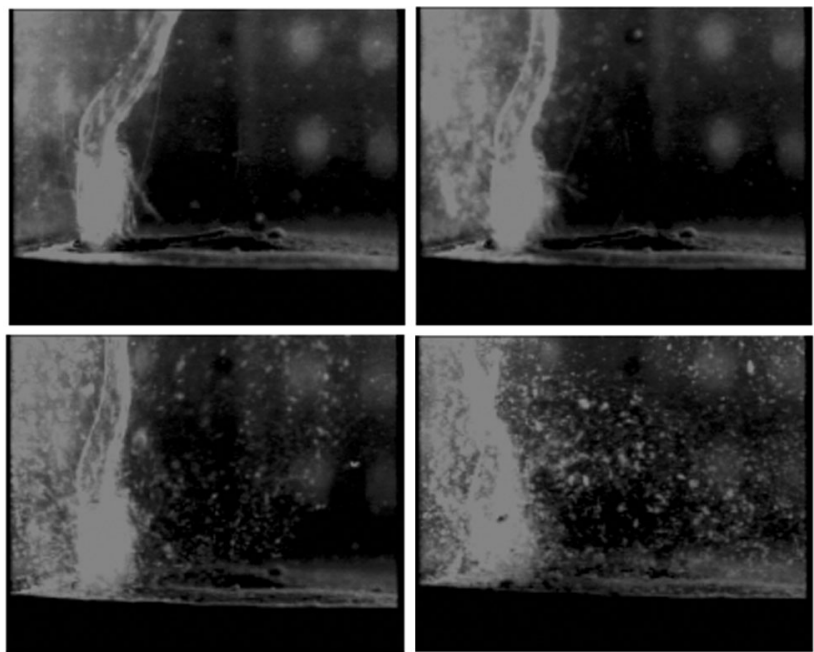

Fig. 5. Mysis mixta. Video sequence of an individual digging up the sediment surface covered with ephippia. Time interval between the first and last image is $44 \mathrm{~s}$
6.0 ephippia $\mathrm{h}^{-1}$ for medium-sized $M$. relicta. In general $M$. mixta $(\mathrm{n}=12)$ ate fewer ephippia than $M$. relicta $(\mathrm{n}=10)$ of the same size $(t=-3.213, \mathrm{p}=0.004$, $\mathrm{df}=20$ ). Medium-sized $M$. relicta ate more ephippia than large ones $(t=$ $-2.357, \mathrm{df}=18, \mathrm{p}=0.037, \mathrm{n}=10$ ).

When ephippia were allowed to settle within the sediment, predation rates were considerably lower, ranging from $<0.1$ ephippia $\mathrm{h}^{-1}$ in large Mysis mixta to 0.3 ephippia $\mathrm{h}^{-1}$ in postspawned $M$. mixta. Postspawned females $(\mathrm{n}=11)$ of $M$. mixta ate ephippia at a higher rate than the large $(\mathrm{n}=12)$ individuals $(t=$ $2.509, \mathrm{p}=0.020, \mathrm{df}=21)$. Feeding rates of large individuals ( $\mathrm{n}=10$ to 12$)$ did not differ statistically significantly from controls $(\mathrm{n}=7)(M$. mixta: $t=0.374, \mathrm{p}=0.713, \mathrm{df}=$ 17; M. relicta: $t=1.050, \mathrm{p}=0.310, \mathrm{df}=15$ ) (Fig. 4B).

\section{Stomach contents}

In the stomach content analyses, pieces of crushed ephippia were found in stomachs of mysids in all treatments of Expt 4. All ephippia were empty, indicating no survival of Bosmina eggs in the digestive tract of Mysis spp.

\section{Behaviour}

On video, mysids were observed feeding on ephippia suspended in water. Ephippia were caught in the feeding current produced by the mysid, and captured and handled by the mysid.

When mysids were placed in the aquarium with a sediment layer, one large individual (ca. $17 \mathrm{~mm}$ ) of Mysis mixta was seen to bury its antennal scales into the sediment and to dig into the sediment surface with its thoracic limbs, causing a remarkable resuspension of benthic material (Fig. 5). During a period of ca. $2 \mathrm{~h}$, this individual frequently processed the sediment surface in the same manner. The digging was estimated to extend into the sediment to a depth of ca. $3 \mathrm{~mm}$.

\section{DISCUSSION}

\section{Feeding rates and preferences}

Predation experiments and stomach content analyses have shown that pelagic mysids of the northern Baltic feed on both calanoid copepods and adult cladocerans (Mohammadian et al. 1997, Viherluoto et al. 
2000, Viherluoto \& Viitasalo 2001a). To our knowledge, however, predation on cladoceran benthic eggs has not been reported to date. Our experiments revealed that mysids are not unselective feeders on cladoceran eggs: small and medium-sized Mysis mixta fed actively on Bosmina ephippia, while they almost completely rejected eggs of Pleopsis polyphemoides, even though they had been starved for $12 \mathrm{~h}$ and no other food was available. Compared to Bosmina ephippia, resting eggs of $P$. polyphemoides are smaller, but they have a tough outer membrane typical of the resting eggs of marine cladocerans (Egloff et al. 1997). The chitinous membrane of ephippia - remains of the Bosmina carapace-seems more fragile and may be more easily broken. Since no whole Bosmina eggs were found in the stomachs of mysids, we believe that live passage of Bosmina eggs through the alimentary tract (as observed in fish and certain invertebrates; Marcus 1984, Flinkman et al. 1994, Saint-Jean \& Pagano 1995) is not possible in mysids.

In the functional response experiment, the mysids fed on Bosmina eggs at a high rate, even though the highest prey densities corresponded to twice the average maximum densities observed in the field (Kankaala 1983, Viitasalo et al. 1995). Viherluoto \& Viitasalo (2001b) also found that Mysis mixta feeding was saturated only at prey densities of 140 to 170 adult copepods $\mathrm{l}^{-1}$, which is far above the highest densities used in our experiment (42 ephippia $\mathrm{l}^{-1}$ ). This suggests that feeding of mysids on Bosmina rarely saturates in the field. A Type I functional response (Holling 1959) has already been reported for mysids feeding on cladoceran prey (Viitasalo \& Rautio 1998). This response type is probably due to the fact that mysids suspension-feed on small and slowly moving prey (Mauchline 1980, Grossnickle 1982) such as Bosmina.

As microplankton did not affect predation on ephippia, we also tested the effect of alternative zooplankton food (Bosmina adults). In Expt 3, the selectivity indices indicated slight preference for live Bosmina adults over ephippia. This may be because swimming zooplankton are hydrodynamically more conspicuous than passively floating prey (e.g. Kiørboe \& Visser 1999) and because the encounter rate between predator and prey is higher when the prey is moving (e.g. Gerritsen \& Strickler 1977). The size difference between Bosmina ephippia and live Bosmina adults is presumably less important (size of ephippia $\sim 460 \mu \mathrm{m}$, and of parthenogenetic adults $\sim 440 \mu \mathrm{m}$; pers. obs.). Furthermore, the protective membrane of the ephippia is not particularly tough, and is probably as easily broken by mysid mouth parts as live Bosmina adults. Apparently mysids do not prefer ephippia over live zooplankton, but we suggest that ephippia may be intensively preyed upon when pelagic food is scarce.

\section{Mysid feeding on cladoceran benthic eggs with sediment}

Both pelagic Mysis species feed on benthic material, such as benthic algae and detritus (Rudstam et al. 1989, Viherluoto et al. 2000). In our experiments, both mysid species fed on Bosmina benthic eggs added on top of the sediment, Mysis relicta at a higher rate than $M$. mixta of the same size. This may be due to $M$. relicta feeding relatively more on benthic material than the more planktivorous M. mixta (Viherluoto et al. 2000). Furthermore, large M. relicta ate fewer ephippia than medium-sized ones, reflecting the zooplanktivorous character of the large mysids (Viherluoto et al. 2000, Lehtiniemi et al. 2002).

Significant loss of ephippia within the sediment was only observed with the largest, postspawned, Mysis mixta and medium-sized M. relicta. As the ephippia probably sank faster than the fine sediment particles, they may have been buried under a sediment layer of 1 to $2 \mathrm{~cm}$ thickness, and were not available for the mysids. In the field, ephippia may also be buried under the sediment relatively quickly after settling. On the other hand, since only the ephippia at the sedimentwater interface are liable to hatch (Uye \& Fleminger 1976), the predatory effect of mysids may still be significant.

The video films revealed that the pelagic mysids may actively process the surface layer of the sediment. On the basis of our observations it is too early to draw conclusions about the significance of this behaviour in the field. We suggest that this behaviour may be associated to the resuspension of food items in order to facilitate their capture either from the water or from the sediment surface. It is notable that digging will also alter the structure and oxygen content of the sediment surface. This can have an additional indirect effect on the survival and hatching of zooplankton eggs, as well as on the distribution of other benthic animals.

Based on our experimental results, we can roughly estimate the possibility of mysids affecting Bosmina eggs in the field. Since ephippia are mainly produced in the fall and start to hatch in spring (Purasjoki 1958, Kankaala 1983), the highest densities of ephippia in the sediment probably occur from October to April (6 mo). Since the majority of mysids remain near the bottom only during daytime (Salemaa et al. 1986, Rudstam et al. 1989), they may have ca. $1800 \mathrm{~h}(10 \mathrm{~h}$ per day) of benthic feeding during this period. In Expt 4, predation rates ranged between 0.1 and 2.8 ephippia $\mathrm{h}^{-1}$ in M. mixta and between 0.2 and 6.0 ephippia $\mathrm{h}^{-1}$ in M. relicta. During the October to April period the total consumption could be 100 to 5010 and 340 to 10860 ephippia mysid ${ }^{-1}$, respectively. Furthermore, the abundance of Bosmina ephippia in the 0 to $1 \mathrm{~cm}$ deep sur- 
face layer of soft bottom sediments in the study area is between 0 and 3 ephippia $\mathrm{cm}^{-3}$ (0 to 30000 ephippia $\mathrm{m}^{-2}$ ) (Viitasalo \& Katajisto 1994), and the average abundance of the 2 Mysis species on the SW coast of Finland may be 50 to 100 ind. $\mathrm{m}^{-2}$ (Salemaa et al. 1986). The fraction of eggs that the mysid population may consume could be estimated from these values. However, because of the many uncertainties in this estimate, we merely conclude that the pelagic mysids of the northern Baltic have the potential to locally affect the abundance of Bosmina eggs by benthic predation.

\section{Conclusions}

This study shows for the first time that mysid shrimps may influence cladoceran population dynamics through predation on their resting eggs. All size classes of the 2 dominant mysid species of the Baltic Sea fed on Bosmina ephippia, both in the water and from the sediment surface. Especially during wintertime, ephippia may be nutritious food for overwintering mysid females that feed on benthic material (Viherluoto et al. 2000). The recently laid ephippia, in turn, may be fed upon in late summer and autumn, when ephippia are produced and sinking, and when weak stratification of the water column induces resuspension of the benthic material in shallow archipelago areas (<35 m; cf. Katajisto et al. 1998).

Mysis mixta and $M$. relicta did not efficiently dig up ephippia mixed with the sediment. Therefore factors affecting the vertical distribution of the eggs are crucial for the impact of mysids on Bosmina eggs. Abiotic and biotic processes such as sedimentation, resuspension and bioturbation affect the position of zooplankton eggs in the sediment. Notably, certain deposit feeding polychaete species transport zooplankton eggs to the sediment surface (Marcus \& Schmidt-Gengenbach 1986), whereas the amphipod Monoporeia affinis spreads the vertical distribution of copepod eggs into deeper strata (Albertsson \& Leonardsson 2000). Investigations on the impact of other benthic invertebrates are necessary to quantify the predatory effect by mysids on zooplankton resting eggs in the Baltic Sea.

Acknowledgements. The Walter and Andrée de Nottbeck Foundation and the Onni Talas Foundation provided financial support for this research. Tvärminne Zoological Station provided the laboratory facilities. T. Sjölund was an invaluable help while collecting mysids and sediment in the field. Special thanks to a group of undergraduate students in the 2001 Baltic Sea Ecology course, who helped with Expt 1B, and to S. Lehtinen, who helped with Expt 4. We thank M. Lehtiniemi, J. Flinkman and 4 anonymous referees for comments on the manuscript and H. Rita for advice with the selectivity statistics.

\section{LITERATURE CITED}

Albertsson J, Leonardsson K (2000) Impact of a burrowing deposit-feeder, Monoporeia affinis, on viable zooplankton resting eggs in the northern Baltic Sea. Mar Biol 136:611-619

Albertsson J, Leonardsson K (2001) Deposit-feeding amphipods (Monoporeia affinis) reduce the recruiment of copepod nauplii from benthic resting eggs in the northern Baltic Sea. Mar Biol 138:793-801

Egloff DA, Fofonoff PW, Onbé T (1997) Reproductive biology of marine cladocerans. Adv Mar Biol 31:79-167

Flinkman J, Vuorinen I, Christiansen M (1994) Calanoid copepod eggs survive passage through fish digestive tracts. ICES J Mar Sci 51:127-129

Gerritsen J, Strickler JR (1977) Encounter probabilities and community structure in zooplankton: a mathematical model. J Fish Res Board Can 34:73-82

Grossnickle NE (1982) Feeding habits of Mysis relicta-an overview. Hydrobiologia 93:101-107

Hansson S, Larsson U, Johansson S (1990) Selective predation by herring and mysids, and zooplankton community structure in a Baltic Sea coastal area. J Plankton Res 12: 1099-1116

Holling CS (1959) The components of predation as revealed by a study of small-mammal predation of the European pine sawfly. Can Entomol 91:293-320

Kankaala P (1983) Resting eggs, seasonal dynamics, and production of Bosmina longispina maritime (P. E. Müller) (Cladocera) in the northern Baltic proper. J Plankton Res 5:53-69

Katajisto T, Viitasalo M, Koski M (1998) Seasonal occurrence and hatching of calanoid eggs in sediments of the northern Baltic Sea. Mar Ecol Prog Ser 163:133-143s

Kearns CM, Hairston NG, Kesler DH (1996) Particle transport by benthic invertebrates: its role in egg bank dynamics. Hydrobiologia 332:63-70

Kiørboe T, Visser AW (1999) Predator and prey perception in copepods due to hydrochemical signals. Mar Ecol Prog Ser 179:81-95

Lehtiniemi M, Viitasalo M, Kuosa H (2002) Diet composition influences the growth of the pelagic mysid shrimp, Mysis mixta (Mysidacea). Boreal Environ Res 7:121-128

Marcus NH (1984) Recruitment of copepod nauplii into the plankton: importance of diapause eggs and benthic processes. Mar Ecol Prog Ser 15:47-54

Marcus NH, Schmidt-Gengenbach J (1986) Recruitment of individuals into the plankton: The importance of bioturbation. Limnol Oceanogr 31:206-210

Mauchline J (1980) The biology of mysids and euphausiids. Adv Mar Biol 18:1-677

Mohammadian MA, Hansson S, De Stasio BT (1997) Are marine planktonic invertebrates food limited? The functional response of Mysis mixta (Crustacea, Mysidacea) in the Baltic Sea. Mar Ecol Prog Ser 150:113-119

Onbé T (1978) Sugar flotation method for sorting the resting eggs of marine cladocerans and copepods from sea-bottom sediment. Bull Jap Soc Sci Fish 44:1411

Pearre S Jr (1982) Estimating prey preference by predators: uses of various indices, and a proposal of another based on $\chi^{2}$. Can J Fish Aquat Sci 39:914-923

Purasjoki KJ (1958) Zur Biologie der Brackwasserkladozere Bosmina coregoni maritima (P. E. Müller). Ann Zool Soc 'Vanamo' 19:1-117

Rudstam LG, Danielsson K, Hansson S, Johansson S (1989) Diel vertical migration and feeding patterns of Mysis mixta (Crustacea, Mysidacea) in the Baltic Sea. Mar Biol 101:43-52 
Rudstam LG, Hansson S, Johansson S, Larsson U (1992) Dynamics of planktivory in a coastal area of the northern Baltic Sea. Mar Ecol Prog Ser 80:159-173

Saint-Jean L, Pagano M (1995) Egg mortality through predation in egg-carrying zooplankters. Studies on Heterobranchus longifilis larvae fed on copepods, cladocerans and rotifers. J Plankton Res 17:1501-1512

Salemaa H, Tyystjärvi-Muuronen K, Aro E (1986) Life histories, distribution and abundance of Mysis mixta and Mysis relicta in the northern Baltic Sea. Ophelia Suppl 4:239-247

Uitto A, Heiskanen AS, Lignell R, Autio R, Pajuniemi R (1997) Summer dynamics of the coastal planktonic food web in the northern Baltic Sea. Mar Ecol Prog Ser 151:27-41

Uye S, Fleminger A (1976) Effects of various environmental factors on egg development of several species of Acartia in southern California. Mar Biol 38:253-262

Viherluoto M, Viitasalo M (2001a) Effect of light on the feeding rates of pelagic and littoral mysid shrimps: a trade-off between feeding success and predation avoidance. J Exp Mar Biol Ecol 261:237-244

Viherluoto M, Viitasalo M (2001b) Temporal variability in functional responses and prey selectivity of pelagic mysid, Mysis mixta, in natural prey assemblages. Mar Biol 138: $575-583$

Editorial responsibility: Otto Kinne (Editor), Oldendorf/Luhe, Germany
Viherluoto M, Kuosa H, Flinkman J, Viitasalo M (2000) Food utilisation of pelagic mysids, Mysis mixta and M. relicta, during their growing season in the northern Baltic Sea. Mar Biol 136:553-559

Viitasalo M (1992) Mesozooplankton of the Gulf of Finland and northern Baltic proper - a review of monitoring data. Ophelia 35:147-168

Viitasalo M, Katajisto T (1994) Mesozooplankton resting eggs: identification and vertical distribution in laminated and mixed sediments. Mar Biol 120:455-466

Viitasalo M, Rautio M (1998) Zooplanktivory by Praunus flexuosus (Crustacea: Mysidacea): functional responses and prey selection in relation to prey escape responses. Mar Ecol Prog Ser 174:77-87

Viitasalo M, Vuorinen I, Saesmaa S (1995) Mesozooplankton dynamics in the northern Baltic Sea: implications of variations in hydrography and climate. J Plankton Res 17: 1857-1878

Viitasalo M, Kiørboe T, Flinkman J, Pedersen LW, Visser AW (1998) Predation vulnerability of planktonic copepods: consequences of predator foraging strategies and prey sensory abilities. Mar Ecol Prog Ser 175:129-142

Zar JH (1984) Biostatistical analysis, 2nd edn. Prentice Hall, Englewood Cliffs, NJ

Submitted: December 3, 2003; Accepted: July 20, 2004 Proofs received from author(s): October 6, 2004 